\title{
Spanish Researchers at the Forefront of Clinical Investigation: the case of quality of life in prostate cancer
}

\author{
Ferran Guedea $\cdot$ Montse Ferrer
}

A s most readers are undoubtedly aware, the appropriate management of localised prostate cancer is a topic of intense debate among physicians, especially considering the lack of comparative randomised clinical trials. A recent systematic review [1] identified 18 randomised trials and 473 observational studies carried out to evaluate the effectiveness of treatments for this disease. However, most of these studies compared variations of a single treatment modality, and among the clinical trials only the Scandinavian prostate cancer group study [2,3] compared radical prostatectomy with the more conservative option of "active surveillance". The Scandinavian study showed that prostatectomy significantly reduced prostate-specific mortality [2] at 6- years follow-up (4.6\% vs. 8.9\%, $p=0.02)$, but overall mortality was not statistically significant [3] until 10 years of follow-up ( $27 \%$ vs. $32 \%, p=0.04)$. The authors of the systematic review [1] concluded that little highquality evidence is available and that the relative benefits and side effects of treatments are not well-characterised, facts that underline the need for new high-quality studies to facilitate clinical recommendations.

However, conducting randomised clinical trials in prostate cancer patients has presented considerable difficulties. Recruitment for the aforementioned Scandinavian clinical trial [2, 3] took more than 10 years (1989-1999). The 2003 Surgical Prostatectomy vs. Interstitial Radiation Interven-

\footnotetext{
F. Guedea (伲)

Radiation Oncology Department

Institut Català d'Oncologia - Hospital Durán y Reynals

Universitat de Barcelona

Av. Gran Via, s/n km, 2,7

ES-08907 L'Hospitalet de Llobregat, Barcelona, Spain

e-mail: guedea@iconcologia.net

F. Guedea

Vice-President

Spanish Society for Radiation Oncology (SEOR)

M. Ferrer

Health Services Research Unit

IMIM-Hospital del Mar

Barcelona Biomedical Research Park

CIBER en Epidemiología y Salud Pública (CIBERESP)

Barcelona, Spain
}

tion Trial (SPIRIT), with an intended sample size of 2000 patients in the USA and Canada, had to be closed due to insufficient enrollment. At the moment, there are two clinical trials ongoing: the 'Prostate Cancer Intervention Versus Observation Trial (PIVOT)' study, designed [4] by the Department of Veterans Affairs and National Cancer Institute (EEUU) with a sample size of 1000 patients under age 75; and the Prostate Testing for Cancer and Treatment Study (ProtecT) [5], performed in the UK, which has attempted to improve recruitment by embedding this trial within qualitative research to make it more acceptable to patients and clinicians. It will be some years before the results of these clinical trials are available and in the meantime doctors face the problem of briefing patients on the many therapeutic options, as recently published in the New York Times (26 February 2008: "A review of prostate cancer leaves men in a muddle").

Even though evidence from randomised clinical trials comparing treatments is not yet available, the Agencies for the Evaluation of Medical Technology of Quebec and Catalonia [6, 7] conducted a systematic review of studies that compared different treatments and included determination of pre- and post-treatment PSA. Two of the studies [8, 9] in that review evaluated the three main treatment options (radical prostatectomy, prostate brachytherapy and external radiotherapy) and found overall biochemical progressionfree survival rates at five years of 70\% [8] and $85 \%$ [9], respectively. More importantly, for low-risk patients, neither study found a statistically significant difference between the 3 treatment groups. These results weaken the established criterion of radical prostatectomy as the first option of treatment for localised prostate cancer and lend support to the greater use of brachytherapy and external beam radiotherapy.

The upshot of all this uncertainty is that other aspects of treatment -in particular, health-related quality of life (HRQL) - have become increasingly important, especially if we bear in mind that locally-confined prostate cancer can be asymptomatic whereas treatment can have serious side effects. Studying the side effects and HRQL may help men and clinicians to decide between treatment options. In this context, interest in understanding how treatments will affect HRQL has grown enormously, and the first longitudinal studies including the main treatment options 
with pre-treatment evaluation and mid-term follow-up have been published recently. Two of these were conducted in the USA [10, 11] and one in Spain, the 'Spanish Multicentric Study on Prostate Cancer' [12], with similar results to those from the USA: sexual dysfunction and urinary incontinence were greatest in the prostatectomy group, impairment of bowel function was highest in the external beam radiotherapy group and urinary irritation symptoms were greatest in the brachytherapy group.

Indeed, the present issue of Clinical and Translational Oncology includes the study of 304 patients treated at the Institut Català d'Oncologia (ICO)/Bellvitge University Hospital with the three main treatment modalities. These results are a subset analysis of the 'Spanish Multicentric Study on Prostate Cancer' [12] carried out by a research group coordinated through the Health Services Research Group (IMIM, Barcelona) and composed of radiation oncologists and urologists from 10 hospitals from all over Spain (Institut Català d'Oncologia, Barcelona; Hospital Universitari de Bellvitge, Barcelona; Instituto Oncológico de Guipúzcoa, San Sebastián; Capio Hospital General de Catalunya, Barcelona; Centro Oncológico de Galicia, La Coruña; Hospital Ramón y Cajal, Madrid; Hospital Re- gional Carlos Haya, Málaga; Hospital Virgen del Rocío, Sevilla; Fundación Puigvert, Barcelona and Hospital de la Santa Creu i Sant Pau, Barcelona).

The Spanish Multicentric group has been very active since it was created several years ago. The group recently published preliminary results of the 3-year follow-up [13] for HRQL in prostate cancer and also developed the Spanish-language version of the Expanded Prostate Cancer Index Composite (EPIC) [14], a questionnaire designed to evaluate the impact of prostate cancer treatment on patient quality of life. We are now working on the 5-year followup (grant PI08/90090 ISCIII - FEDER) to assess long-term effects of these treatments.

To conclude, the aim of this editorial is to highlight the relevant research of this group in order to illustrate what can be accomplished when Spanish researchers apply their knowledge, skills, and resources in a focused way. There is no reason why we should not be at the forefront of research and publication in our respective areas of expertise. The opportunity to provide leadership on the wider world stage is available, but it is up to us to seize the initiative, to expand our horizons, and above all, to act-with energy, passion, and conviction.

\section{References}

1. Wilt TJ, MacDonald R, Rutks I et al (2008) Systematic review: comparative effectiveness and harms of treatments for clinically localized prostate cancer. Ann Intern Med 148:435-448

2. Holmberg L, Bill-Axelson A, Helgesen F et al (2002) A randomized trial comparing radical prostatectomy with watchful waiting in early prostate cancer. N Engl J Med 347:781-789

3. Bill-Axelson A, Holmberg L, Ruutu M et al (2005) Radical prostatectomy versus watchful waiting in early prostate cancer. N Engl J Med 352:19771984

4. Wilt TJ, Brawer MK (1997) The Prostate Cancer Intervention Versus Observation Trial (PIVOT). Oncology (Huntingt) 11:1133-1139

5. Donovan J, Mills N, Smith M et al (2002) Quality improvement report: Improving design and conduct of randomised trials by embedding them in qualitative research: ProtecT (prostate testing for cancer and treatment) study. Commentary: presenting unbiased information to patients can be difficult. BMJ 325:766-770
6. CETS (2000) Conseil d'évaluation des technologies de la santé du Québec (CETS). Brachytherapy and prostate cancer. Conseil d'évaluation des technologies de la Santé de Québec (CETS), 1-25, Montréal: CETS; 2000. Available at: http:// www.aetmis.gouv.qc.ca/site/en_publications_liste. phtml. Accessed on 18 June, 2009.

7. Oliva G (2000) Braquiteràpia en el Càncer de Pròstata. AATM, Barcelona, pp 1-59

8. Stokes SH (2000) Comparison of biochemical disease-free survival of patients with localized carcinoma of the prostate undergoing radical prostatectomy, transperineal ultrasound-guided radioactive seed implantation, or definitive external beam irradiation. Int J Radiat Oncol Biol Phys 47:129-136

9. D'Amico AV, Whittington R, Malkowicz SB et al (1998) Biochemical outcome after radical prostatectomy, external beam radiation therapy, or interstitial radiation therapy for clinically localized prostate cancer. JAMA 280:969-974

10. Sanda MG, Dunn RL, Michalski J et al (2008) Quality of life and satisfaction with outcome among prostate-cancer survivors. N Engl J Med 358:1250-1261
11. Litwin MS, Gore JL, Kwan L et al (2007) Quality of life after surgery, external beam irradiation, or brachytherapy for early-stage prostate cancer. Cancer 109:2239-2247

12. Ferrer M, Suarez JF, Guedea F et al (2008) Healthrelated quality of life 2 years after treatment with radical prostatectomy, prostate brachytherapy, or external beam radiotherapy in patients with clinically localized prostate cancer. Int J Radiat Oncol Biol Phys 72:421-432

13. Ferrer M, Rueda JR, Latorre K, Gutiérrez I, Grupo Multicéntrico Español de Cáncer de Próstata Localizado (2008) Efectividad a largo plazo de la prostatectomía radical, la braquiterapia y la radioterapia conformacional externa 3D en el cáncer de próstata órgano-confinado. Plan de Calidad para el Sistema Nacional de Salud, Madrid. Ministerio de Sanidad y Consumo. Agència d'Avaluació de Tecnologia i Recerca Mèdiques de Cataluña. Informes de Evaluación de Tecnologías Sanitarias, AATRM núm. 2006/08

14. Ferrer M, Garin O, Pera J et al (2009) [Evaluation of the quality of life of patients with localizad prostate cancer: validation of the Spanish version of the EPIC]. Med Clin (Barc) 132:128-135 